\title{
Awareness and use of Wi-Fi infrastructure in student's community: a case study Pondicherry University on campus students
}

\author{
Mangkhollen Singson \\ Assistant Professor \\ Dept of Library \& Information Sc \\ Pondicherry University
}

\author{
Rajesh \\ Assistant Librarian \\ Sri .Venkateshwaraa Medical College Hospital \& \\ Research Centre, Pondicherry
}

\begin{abstract}
Technology can be a boon to the learning community with new technology making an inroad to the teaching and research domain. Wi-Fi for instance has a tremendous contribution in the way students connect and access information. This paper looks into the level of Wi-Fi awareness and the problem face by the student community in the campus and their level of competence. The study involved a questionnaire survey of students $(n=100)$ and revolves around the students residing in the campus hostel and as such the off campus students were ignored for the study. The parameter for the research was ICT literacy, Wi-Fi awareness, connectivity problem, usage, gadget preference. The outcomes of the finding suggest that although the calls for radical transformations in educational approaches may be legitimate it would be misleading to ground the arguments for such change solely in students' opinion and that the infrastructure indeed shows a great deal of benefit to the student in the way they connect online.The finding also identified the problem in WiFi hotspots and the coverage.
\end{abstract}

\section{Introduction:}

The "digital divide" is a term coined to address the inequalities of computer ownership and internet access and use (Servon, 2002) and information asymmetry is a problem when it comes to the deprive section being devoid of information at a right time at a right place. Technology can be a boon to the educational system in communication and teaching. Wi-Fi for intance can monitor an area as a group and communicate using centralized control or ad hoc configuration 
and provide a low cost solution. With more and more of these wireless devices being mobile there is a constant challenge to provide high quality, reliable and secure communication between these devices. Wi-Fi hotspots offered free of charge in public places that anyone could use to access the internet (Powell Alison, 2008) thereby allowing the students access all the electronic information needs. The presence of the Wi-Fi within a define range of hotspot enables the student avoid the trouble of accessing through the cable LAN which restricts the student from mobility, WI-FI is proving to be the default Internet access technology.

This level of popularity and growth of WLANs has also introduced a new challenge in the way corporate and other networks are traditionally managed. The key challenge is around the manageability of WLANs alongside their wired counterparts without requiring structural changes to the overall management techniques or processes and without significantly increasing the total cost of ownership of network management. Unless significant progress is made in the WLAN management technologies and processes, WLANs will have difficulty in becoming one of the mainstream networking technologies in the enterprise and other deployments. This is because, network service providers of all kinds must offer a reliable and consistent network quality of service no matter how the networks are accessed, else they will be under scrutiny for not meeting their service level objectives, and they cannot provide that kind of service without a consistent and structured management practice across their wired and wireless network.

\section{Wireless LAN?}

A wireless LAN (WLAN) is a data transmission system designed to provide locationindependent network access between computing devices by using radio waves rather than a cable infrastructure. In the corporate enterprise, wireless LANs are usually implemented as the final link between the existing wired network and a group of client computers, giving these users wireless access to the full resources and services of the corporate network across a building or campus setting. WLANs are on the verge of becoming a mainstream connectivity solution for a broad range of business customers. The wireless market is expanding rapidly as businesses discover the productivity benefits of going wire-free. According to Frost and Sullivan, the wireless LAN industry exceeded $\$ 300$ million in 1998 and is projected to grow $\$ 1.6$ billion in 
2005. To date, wireless LANs have been primarily implemented in vertical applications such as manufacturing facilities, warehouses, and retail stores. The majority of future wireless LAN growth is expected in healthcare facilities, educational institutions, and corporate enterprise

office spaces. In the corporation, conference rooms, public areas, and branch offices are likely venues for WLANs. The widespread acceptance of WLANs depends on industry standardization to ensure product compatibility and reliability among the various manufacturers. The Institute of Electrical and electronics Engineers (IEEE) rectified the original 802.11 specification in 1997 as the standard for wireless LANs. That version of 802.11 provides for $1 \mathrm{Mbps}$ and $2 \mathrm{Mbps}$ data rates and a set of fundamental signaling methods and other services.

\section{OBJECTIVE OF THE STUDY:}

The main objective of the present study is to

1. find out the student community awareness on availability of Wi-Fi connectivity.

2. better understand the student purpose of using Wi-Fi.

3. understand the minute problem face by the student community.

4. study the level of ICT know how of Pondicherry university students'.

\section{WI-FI INFRASTRUCTURE IN PONDICHERRY UNIVERSITY}

The main campus of the University has an area of 780 acres spread on either side of the East Coast Road with the large chunk on the landward side of the road. The land is an invaluable gift from the people and the Government of Puducherry for the establishment of the University. The land gently rolls down to the beaches and is interspersed with lovely woods. Cut by a picturesque and deep ravine, this idyllic campus is on the fast track to developing into an ideal breeding ground for innovation and creativity.

\section{Local Area Network (LAN) of Pondicherry University.}






Figure 1: Diagrammatic representation of Pondicherry University LAN

The Pondicherry University terrain can be put into coastal area, with lots of grove and plantations. The structures in the university are stone Masonries with few exemptions like Department of Mass Communication. The campus is fully covered with thick groves as blanket which is the barrier for wireless connectivity. Considering this, suggestion were incorporated thereby using high power RF, based on the condition and situation, individual AP's were place in a structure to increase the serviceable area.

\section{Design:}

Since most of the buildings are very close, they were grouped into one unit and the whole campus into units. The list of which are listed below:

\begin{tabular}{|c|c|c|}
\hline UNIT & LOCATION & TECHNOLOGY INSTALLATION \\
\hline
\end{tabular}




\begin{tabular}{|c|c|c|}
\hline $\mathbf{I}$ & $\begin{array}{l}\text { a) Administration building } \\
\text { (Admin), } \\
\text { b) Auditorium } \\
\text { c) Bank } \\
\text { d) Post office } \\
\text { e) Landscape near Students Service } \\
\text { centre (SSC) and } \\
\text { f) SSC. }\end{array}$ & $\begin{array}{l}\text { - The indoor AP's will be wall mounted using } \\
\text { 3" G.I Pole. Since the AP's what we are } \\
\text { going to use are AAP -Adaptive Antenna } \\
\text { Polarity technology (a patent technology } \\
\text { from ubiquity). } \\
\text { - APP is antenna arrays with smart signal } \\
\text { processing algorithms used to identify } \\
\text { spatial signal signature such as the direction } \\
\text { of arrival (DOA) of the signal, and use it to } \\
\text { calculate beam forming vectors, to track and } \\
\text { locate the antenna beam on the } \\
\text { mobile/target. The antenna could optionally } \\
\text { be any sensor. } \\
\text { Smart antenna techniques are used notably } \\
\text { in acoustic signal processing, track and scan } \\
\text { RADAR, radio astronomy and radio } \\
\text { telescopes, and mostly in cellular systems } \\
\text { like W-CDMA and UMTS. }\end{array}$ \\
\hline Unit II & $\begin{array}{l}\text { a) Management Studies both new and } \\
\text { old block } \\
\text { b) Mass media } \\
\text { c) Physical Education Department } \\
\text { and Adjoining Groves }\end{array}$ & $\begin{array}{l}\text { - } 12 \text { AP's out of which } 7 \text { was wall mounted } \\
\text { and rest pole mounted }\end{array}$ \\
\hline $\begin{array}{l}\text { Unit } \\
\text { III }\end{array}$ & $\begin{array}{l}\text { a) Boy's hostel, Grove's and the } \\
\text { bushy areas }\end{array}$ & $\begin{array}{l}\text { - Covered by PowerStation } 2 \text { external with } 16 \\
\text { dbi Omni antenna } \\
\text { - Hostel blocks have } 30 \text { and Odd AP's to } \\
\text { cover the maximum region. }\end{array}$ \\
\hline IV & a) Stadium and nearby bushy region & $\begin{array}{l}\text { AP's fixed on pole mount and the powered } \\
\text { from nearest men's hostel block }\end{array}$ \\
\hline $\mathbf{V}$ & $\begin{array}{lccc}\text { a) } \mathrm{DDE}, \quad \mathrm{MBA} & \text { block } & \text { and } \\
\text { surrounding Block } & & \end{array}$ & \\
\hline
\end{tabular}




\begin{tabular}{|l|l|l|}
\hline VI & $\begin{array}{l}\text { a) Department of Mathematics } \\
\text { b) Physics and } \\
\text { c) The lecture hall }\end{array}$ & \\
\hline $\begin{array}{l}\text { Unit } \\
\text { VII }\end{array}$ & $\begin{array}{l}\text { a) Library } \\
\text { b) The unit V, VI, VII covers all the } \\
\text { major blocks }\end{array}$ & $\bullet$ 46 AP's and bullets is used \\
\hline $\begin{array}{l}\text { Unit } \\
\text { VII }\end{array}$ & $\begin{array}{l}\text { a) Vice Chancellors residence } \\
\text { b) Cultural hall. }\end{array}$ & $\begin{array}{l}\text { We have used 3 AP's in VC's residence and } \\
5 \text { AP's in cultural hall. }\end{array}$ \\
\hline
\end{tabular}

Table 1: Designing phase of Pondicherry Wi-Fi campus Network

\section{Phases of the project:}

The basic design is based upon the hybrid of DSS \&WSS. The Wi-Fi installation will cover $90-95 \%$ of the university area. The rest of the area will have s weak signal due to plantations and the reserved forest area inside the campus.

Each group of Buildings have OFC termination which will in turn terminated in a switch from which the AP's will be connected where AP's are powered using POE. The deployment phase is represented as follows:

Figure 2: Wi-Fi Installations phase

\section{Product used in campus wide wireless in Pondicherry University}

\begin{tabular}{ccc}
\hline Sl.No & Product Description & Quantity \\
1 & Ubiquity Nano Station 2 & 91 \\
2 & Ubiquity Power Station 2 & 21 \\
3 & Ubiquity Power Station 2 External & 8 \\
4 & Ubiquity Bullet 2 & 18 \\
5 & Antenna & 34 \\
\hline
\end{tabular}




\begin{tabular}{ccc}
\hline 6 & Special PoE & 26 \\
7 & Poles & 80 No's \\
8 & STP Cat5e Cable & 17 Boxes \\
9 & Converter Plugs & 125 \\
& & \\
\hline
\end{tabular}

Table 2. List of Infrastructure Product used in campus wide wireless in Pondicherry University

\section{Security: Squid Authentication:}

The goal is to integrate Squid with Server 2003 Active Directory through Samba (Winbind + Kerberos). The university is introducing "Win2K3" server as the authentication server. On the proxy servers only three files have to be edited which are "squid.conf", "krb5.conf" and "smb.conf". Besides that, Samba and Kerberos rpm is also installed. There is no need to restart the proxy servers or even squid proxy service for that matter.

The installation doesn't take more than an hour. As for granting privilege, users belonging to a particular group (Inet Access Group) in Active Directory will be able to have web access after authentication. Some users (especially Wired Users) are allowed to browse without authentication via squid acls. This Squid acls also prevents the User's abuse or user logging from many machines/IP at the same time (i.e simultaneous logins) will be prevented through.

\section{METHODOLOGY OF THE STUDY:}

The data was collected using a paper-based questionnaire. The aim of the questionnaire was to examine the extent of Wi-Fi technology use amongst this target group. The paper questionnaire was handed out at the end of a selected number students present at the university campus. Questionnaires were given randomly, based on student residing in the university campus. The survey was available for 3 weeks and 100 members $(\mathrm{N}=100)$ out of 3500 students in the 
university responded to the invitation by completing the survey. All responses were anonymous and no personal details such as email or IP addresses were collected thereby ensuring privacy. The survey comprised of closed ended questionnaire organized around four topics. These were: (1) educational background, (2) facilities of Wi-Fi (3) purpose of usage, and (4) ICT literacy. For purposes of clarity, the discussion and results will be presented organized around these four topics with the results.

\section{REVIEW OF RELATED LITERATURE:}

The overarching research question guiding the literature review is: how does the literature on Wi-Fi use suggest as the appropriate frameworks and concept for describing and analyzing academic perusal. Internet usage rates per capita are now growing at faster rates in poor countries than in rich countries (Fink and Kenny, 2003). According to Johan Lundin ( 2010 ) over the past 10 years the capacity of a regular, commercial of the shelf laptop has certainly increased. Today, the difference in capacity between a desktop machine and a laptop is rather limited, at least in relation to the way that most of us use our computers. And at the same time, the weight and price have dropped significantly. It is difficult to get reliable and global data on computer sales, but 2005 is argued to be the year when laptops started to sell more than desktop computers (Singer, 2005). Given the widespread adoption of mobile technology among students, combined with increased possibilities for network access (such as WiFi connections in classrooms and across university campuses), and extended battery life, it is understandable that more and more students bring laptops to the classroom. In this sense, the students themselves make computers an important part in their educational activities. Today, teachers expect students to deliver papers written on computers, expecting them to be able to use spell-check, count words, etc. Students are expected to use the digital resources of university libraries, read e-mails, get information about schedules and upload their assignments online. And there has been an increase in the usage of consortia within the campus as the usage increases the cost benefit of electronic resources in the given institution will prove to be effective. 


\section{DATA INTERPRETATION AND ANALYSIS}

\section{Survey Goals and Rationale}

The survey for this study was designed with the primary goal of better understanding the factors that motivates students to access Wi-Fi network in the university. It was also hoped that the survey responses would illuminate and highlights the problem associated in accessing wireless university network at a broader level. Specifically, the questionnaire explores whether students are aware of the Wi-Fi existence and the in-depth behaviors and purpose of the residential student using Wi-Fi network. The study is primary targeted at the students residing within the campus and having access to the connectivity.

\section{Gender ratio of the population:}

The demographics of survey participants varied in terms of age, education levels and the subject, but were otherwise homogeneous. Of the 100 survey respondents who identified their gender, all but three were male. Just five people reported their ages as between 20 and 29 yearsold, as the study field concentrated only on the student's environment. Post graduate responded maximum with $85 \%$ which constituted $46 \%$ male and $39 \%$ female. M.Phil on the other hand constituted the second highest with the $10 \%$ and the last constitute the Ph.D scholars. The Ph.D scholar and M.Phil is the niche user of information as their information needs are diverse and therefore a further study is required on their perception on Wi-Fi technology.

\begin{tabular}{|c|c|c|c|}
\hline Subject & Male & Female & Total \\
\hline Post Graduate & 46 & 39 & 85 \\
\hline Mphil & 7 & 3 & 10 \\
\hline Ph.D & 5 & & 5 \\
\hline
\end{tabular}

Table3. Gender percentage of the sample 


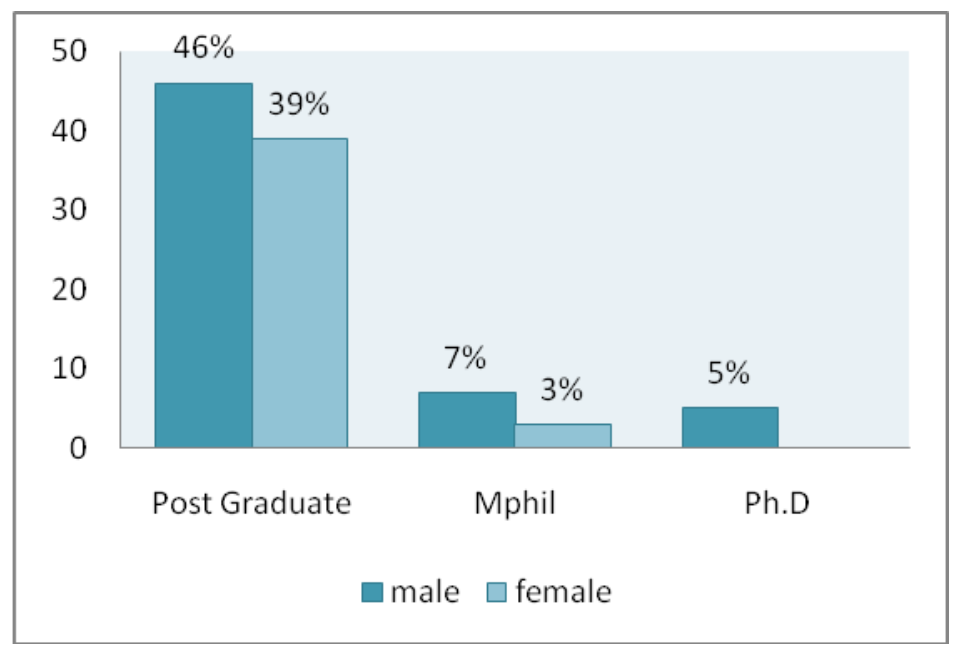

Figure3: Male/ Female respondent percentage.

The average age of the respondents were at 23 years as the given sample site is a university students. Here, the faculty perception and views were not taken into consideration as the study was confine to the students alone.

\section{Computer use}

Computer use among the students were ask for ICT awareness and interestingly $99 \%$ of the respondent except one said they have use or are using computer on a daily basis. This question helps us in building asking the desired information.

\begin{tabular}{|lcc|}
\hline Respondent & Yes & No \\
\hline MA & 84 & 1 \\
\hline Ph.D & 5 & 0 \\
\hline Mphil & 10 & 0 \\
\hline TOTAL & 99 & 1 \\
\hline
\end{tabular}

Table 4: Respondent use of computer

\section{School wise distribution:}

The sample population in the case of subject were scattered randomly, of which there are 85 student are post graduate, M.Phil are 10 and $\mathrm{PhD}$ student constitute 5 in numbers. From the given population Social Science constitute the highest no participant with $69 \%$ of the total 
population and humanities constitute a descent percent with $17 \%$ and lastly the science student group constitute the last with a total strength of 14 .

\begin{tabular}{|l|l|l|l|l|}
\hline Subject & M.A & PhD & M.Phil & Total \\
\hline Humanities & 16 & 1 & 0 & 17 \\
\hline Arts & 0 & 0 & 0 & 0 \\
\hline Science & 14 & 0 & 0 & 14 \\
\hline Soc.sci & $\mathbf{5 5}$ & $\mathbf{4}$ & $\mathbf{1 0}$ & 69 \\
\hline
\end{tabular}

Table5: School wise distribution of selected sample

Since, the questionnaire were distributed randomly, the output result prove to be domination by social science groups.

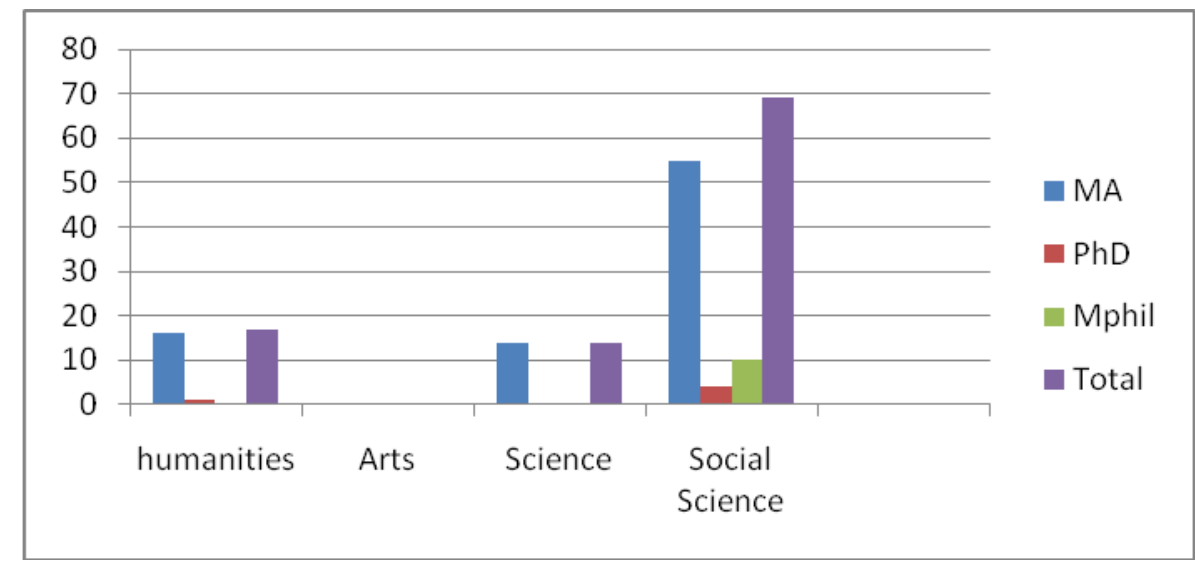

Figure 4: Percentile of subject wise distribution of the given sample.

\section{Computer literacy and purpose of using computer:}

\begin{tabular}{ccccc}
\hline \multicolumn{5}{c}{ Ph.D scholars } \\
\hline internet & entertainment & $\mathbf{R} \boldsymbol{\&} \mathbf{D}$ & acad. & Others \\
$\mathbf{3}$ & 5 & 1 & 2 & $\mathbf{4}$ \\
$\mathbf{3}$ & 5 & 1 & 2 & $\mathbf{4}$ \\
$\mathbf{2}$ & 3 & 4 & & $\mathbf{1}$ \\
$\mathbf{1}$ & 3 & 4 & & $\mathbf{2}$ \\
$\mathbf{2}$ & 3 & 4 & & $\mathbf{1}$ \\
$\mathbf{1 1}$ & 19 & 14 & 4 & $\mathbf{1 2}$ \\
\hline
\end{tabular}

Table 6: Purpose of using computer 
Respondents opinion of using computer was analyze and it was very interesting to find that among the research scholars entertainment seems to be the purpose driven for using a computer followed by research.

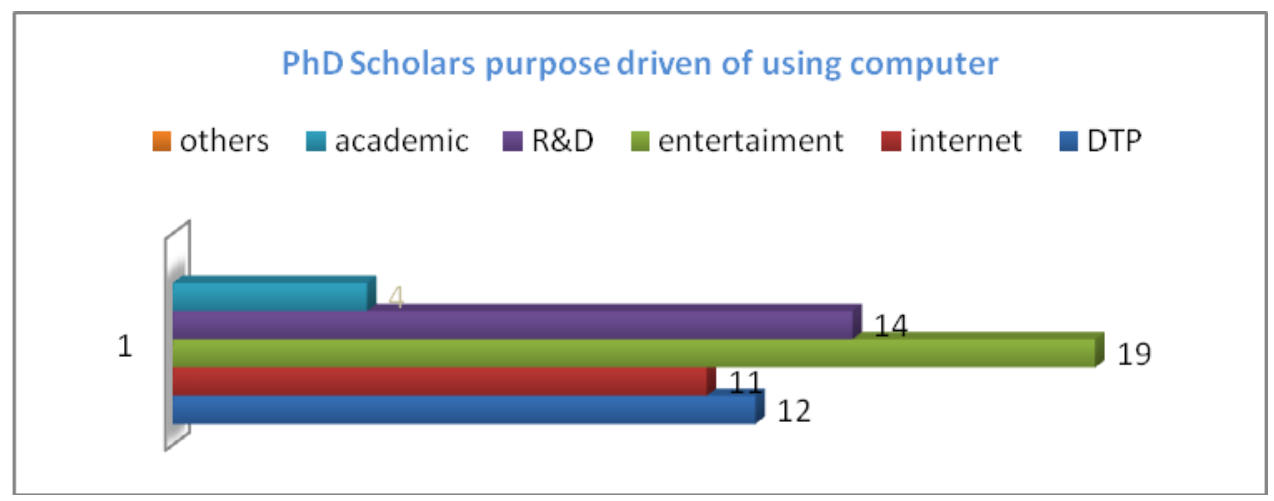

Figure 5: Diagrammatic representation of respondent purpose of using a computer

\section{Awareness of Wi-Fi facility in campus:}

Besides the computer literacy study, the respondent were asked on their knowledge on the existence of university Wi-Fi facility, and it was found that $62.9 \%$ of the Post Graduate were aware of the existence and $9.35 \%$ of the Post Graduate responded as not being aware of the facilities. On the other hand the scholars showed 100\% of the facilities. Even though the sample population among the Ph.D scholar and M.Phil student is small in size, it proves that there is a high interaction and awareness program among the Research Scholars as information sharing and interaction are higher among scholars.

\begin{tabular}{|c|c|c|c|c|c|c|}
\hline Responds & PG & Percentage & $\begin{array}{c}\text { Research } \\
\text { Scholars }\end{array}$ & Percentage & M.Phil & Percentage \\
\hline Yes & 74 & $62.9 \%$ & 5 & 100 & 10 & $100 \%$ \\
\hline No & 11 & $9.35 \%$ & & & & \\
\hline
\end{tabular}

Table 7: Awareness of Campus WI-Fi facility 


\section{Awareness of Campus Wi-Fi}

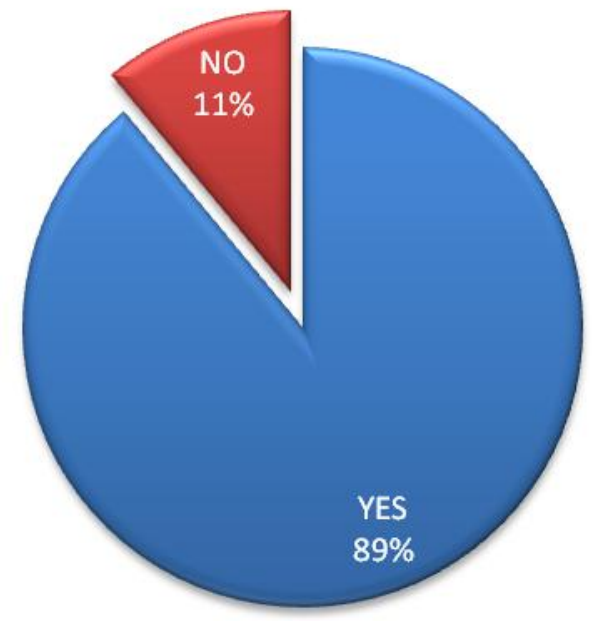

Figure 6: Percentage of awareness of Wi-Fi

\section{Usage of Wi-Fi:}

From awareness study of the Wi-Fi, it was move to the student usage of Wi-Fi. Here, it was found that $85 \%$ of the total population sample have use $\mathrm{Wi}-\mathrm{Fi}$ and have access to be as $15 \%$ of them have never use the facility and have no access to it.

Narrowing it down into different entity, it was found that the Post Graduate student constitute 84 respondent and the highest population out of which $59.5 \%$ have responded to have used $\mathrm{Wi}-\mathrm{Fi}$ and $12.75 \%$ of the population have responded negatively. On the other hand it was very interesting to see that Ph.D scholars and M.Phil student respondent $100 \%$.

Research Scholar in a university is provided with different scholarships and as a result have better medium of accessing the resources in the campus.

\begin{tabular}{|c|c|c|c|c|c|c|c|}
\hline Responds & PG & $\%$ & Research Scholars & $\%$ & M.Phil & $\%$ & Total \\
\hline Yes & 70 & $59.5 \%$ & 5 & 100 & 10 & 100 & $85 \%$ \\
\hline No & 15 & $12.75 \%$ & & & & & $15 \%$ \\
\hline
\end{tabular}

Table 8. Use of campus Wi-Fi

\section{Location of accessing Wi-Fi facility:}

Respondents were asked the location where they are usually surf the internet? There was a mixed responds on the part of the given sample $\mathrm{s} 12.1 \%$ of the total population had not 
responded, were as majority of $66 \%$ of the total population responded to using Wi-Fi in the residential hostel and $20 \%$ of the sample population did access in the library. Preference on location was given to hostel as this allows the surfer to have access to internet resources within his comfort zone. Thereby, allowing him to increase his time frame.

\begin{tabular}{|c|c|c|c|c|c|c|}
\hline LOCATION & PG & $\begin{array}{c}\text { PERCENTAG } \\
\text { E }\end{array}$ & $\begin{array}{c}\text { RESEARCH } \\
\text { SCHOLARS }\end{array}$ & PERCENTAGE & M.PHIL & PERCENTAGE \\
\hline HOSTEL & 55 & $46.75 \%$ & 4 & $0.2 \%$ & 7 & $0.7 \%$ \\
\hline LIBRARY & 16 & $13.6 \%$ & 1 & $0.05 \%$ & 1 & $0.1 \%$ \\
\hline $\begin{array}{c}\text { Zero } \\
\text { responds }\end{array}$ & 14 & $11.9 \%$ & 0 & & 2 & $0.2 \%$ \\
\hline
\end{tabular}

Table 9: Desired location of accessing Wi-Fi

\section{Preference of gadget:}

\begin{tabular}{|c|c|c|c|c|c|l|}
\hline GADGET & $\begin{array}{l}\text { POSTGRADUATE } \\
\text { (N=80) }\end{array}$ & $\%$ & $\begin{array}{l}\text { RESEARCH } \\
\text { SCHOLARS } \\
(\mathbf{N = 5 )}\end{array}$ & $\begin{array}{l}\text { M.PHIL } \\
\text { (N=10) }\end{array}$ & $\%$ \\
\hline Laptop & 58 & $49.3 \%$ & 5 & $100 \%$ & 8 & $0.8 \%$ \\
\hline Palmtop & 5 & $4.25 \%$ & & & & \\
\hline Others & 13 & $11.05 \%$ & & & 1 & $0.1 \%$ \\
\hline $\begin{array}{c}\text { No } \\
\text { responds }\end{array}$ & 9 & & & & 1 & $0.1 \%$ \\
\hline
\end{tabular}

Table 10: Medium of accessing Wireless internet in the campus

Preference or the medium of accessing is one of the important factors that need to be address. From the present study, students were provided with questionnaire on their preference of gadget and there was a holistic response to the question with $71 \%$ of the total sample population prefers laptop as the favorite medium of accessing Wi-Fi were as $14 \%$ uses other medium of gadget that was not enlisted, this being the presence of latest development of new gadget such as the presence of $3 \mathrm{G}$ enable phones or inbuilt $\mathrm{Wi}-\mathrm{Fi}$ phone in the market. The research scholars who have access to gadget equipment have better statistic as compared to the Post Graduate students. 


\section{Preference of gadget}

$\square$ laptop $\square$ palmtop $\square$ others $\square$ zero responds

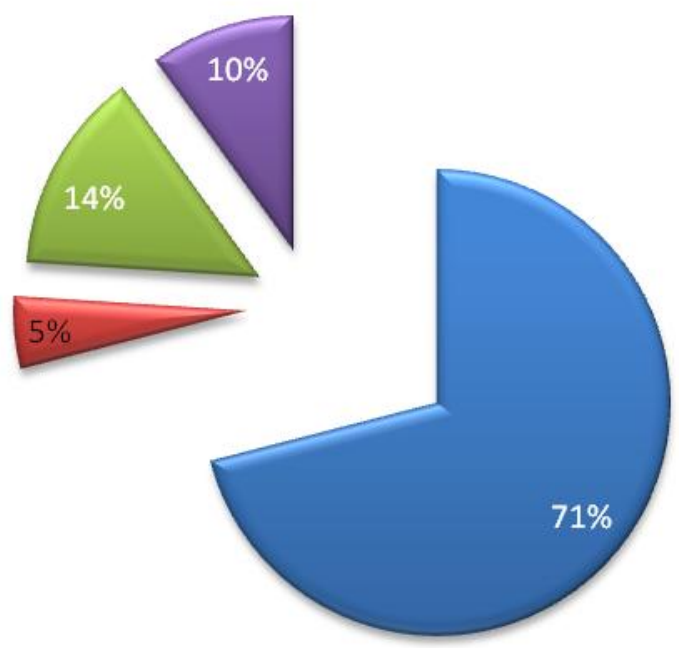

Figure 7 : Percentile representation of gadget preference of students

\section{Ranking of Wi-Fi speed in the university campus:}

Speed of internet really matters in a long run as maximizing the usage will indirectly have impact on the cost benefit of Wi-Fi installation. Higher the usage, higher is the benefit in accessing information.

\begin{tabular}{|l|l|l|l|l|l|l|l|}
\hline \multicolumn{1}{|c|}{ Ranking } & $\begin{array}{c}\text { PG } \\
(\mathbf{N = 8 0})\end{array}$ & Percentage & $\begin{array}{c}\text { Research } \\
\text { Scholars } \\
(\mathbf{N = 5})\end{array}$ & Percentage & $\begin{array}{c}\text { M.Phil } \\
(\mathbf{N}=10)\end{array}$ & Percentage & Total \\
\hline Excellent & 2 & $2.35 \%$ & 1 & $20 \%$ & & & 3 \\
\hline Very good & 9 & $10.58 \%$ & 1 & $20 \%$ & 1 & $10 \%$ & 11 \\
\hline Good & 30 & $35.29 \%$ & 2 & $40 \%$ & 5 & $50 \%$ & 37 \\
\hline Poor & 28 & $32.94 \%$ & 1 & $20 \%$ & 4 & $40 \%$ & 33 \\
\hline Very poor & 13 & $15.29 \%$ & & & & & 13 \\
\hline $\begin{array}{l}\text { Zero } \\
\text { respond }\end{array}$ & 03 & $3.5 \%$ & & & & & \\
\hline
\end{tabular}

Table 11 : Ranking of Wi-Fi speed in the university campus

From the above illustration, it was found that only $2 \%$ of the students felt that the speed is in a excellent speed were as the maximum felt the speed to be an average, with $37 \%$ felt good and 
$33 \%$ felt that it was poor. This gave the opinion that there is a mix responds of good and bad internet speed.

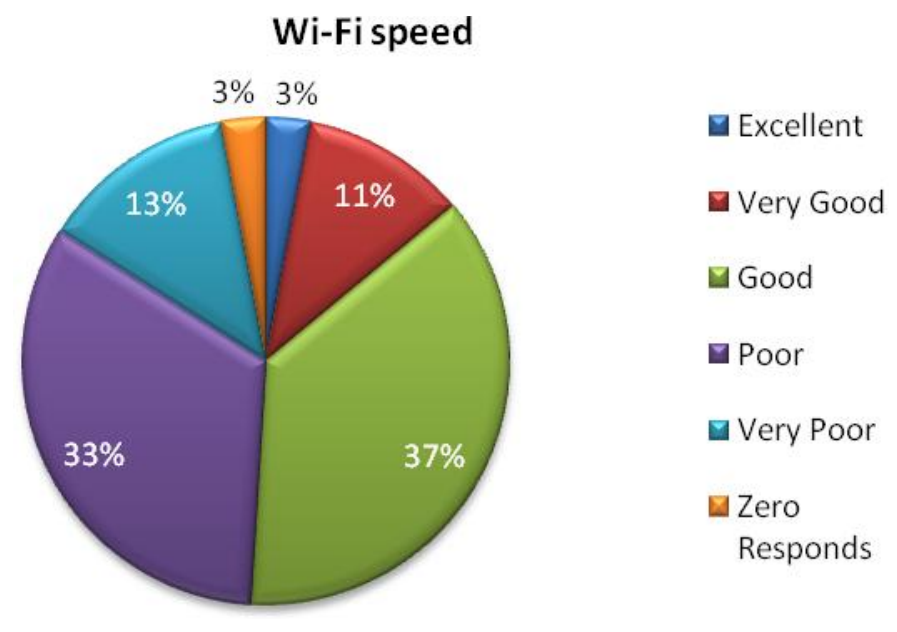

Figure 8: Ranking of Wi-Fi speed

\section{Problem face while surfing:}

Responses on the technical problems face while surfing on a Wi-Fi shows an interesting view of the scenario. The Post Graduate with 55.25\% respondent felt that they indeed have problems while accessing Wi-Fi and $11.05 \%$ felt that they don't have technical problem.

It was found that research scholars of both M.Phil and Research Scholar had no problem in surfing. Therefore the post graduate student fasces more problem while surfing.

\begin{tabular}{|l|l|l|l|l|l|l|}
\hline Responds & PG & Percentage & $\begin{array}{l}\text { Research } \\
\text { Scholars }\end{array}$ & Percentage & M.Phil & Percentage \\
\hline Yes & 65 & $55.25 \%$ & 04 & $0.2 \%$ & 08 & $0.8 \%$ \\
\hline No & 13 & $11.05 \%$ & 01 & $0.05 \%$ & 02 & $0.2 \%$ \\
\hline $\begin{array}{l}\text { Total } \\
\text { responds }\end{array}$ & 78 & $66.3 \%$ & 05 & & 10 & \\
\hline $\begin{array}{l}\text { Zero } \\
\text { responds }\end{array}$ & 07 & $5.95 \%$ & 0 & & 0 & \\
\hline
\end{tabular}

Table 12: Problems face while accessing campus Wi-Fi

\section{Assistance requirement of the respondent}


Respondents were further if assistance to the problem is needed and $60 \%$ felt that assistance is needed and regular service is required so to meet their grievances. The following chart shows a better picture of what the respondent have felt. Maximum being the post graduate.

\begin{tabular}{lll}
\hline & Yes & No \\
\hline Ph.D & 3 & 2 \\
M.A & 60 & 17 \\
Mphil & 10 & \\
Total & 73 & 19 \\
\hline
\end{tabular}

Table 13: Assistance required

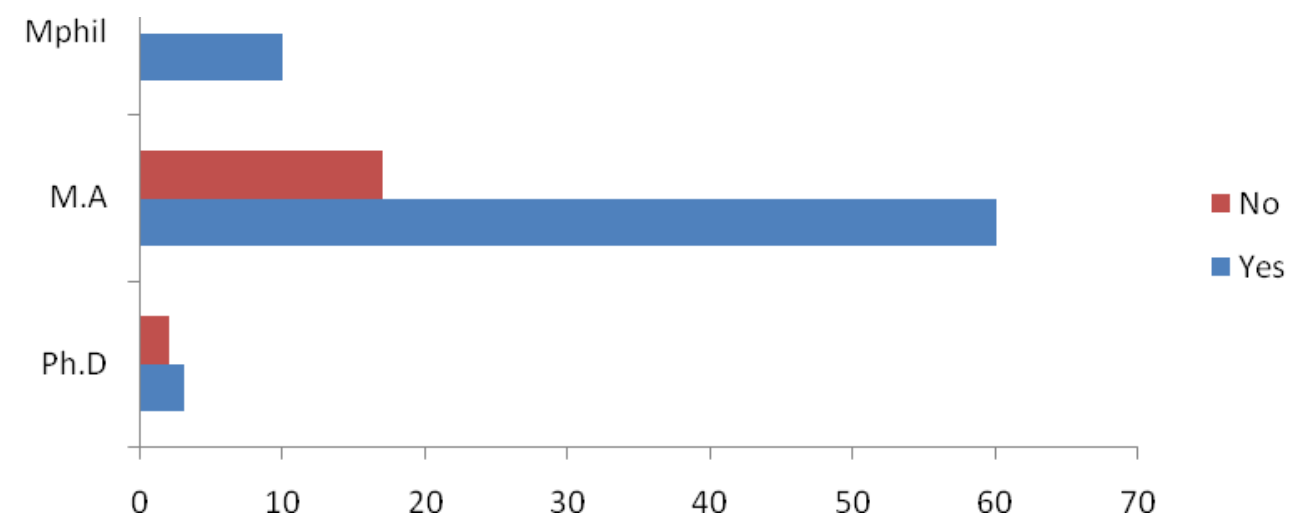

Figure 9: Graphical representation of assistance required

It was very interesting to see that M.Phil student required no assistance to their problem, which indicates that ICT literacy rate is high for M.Phil scholars.

\section{Modes of assistance:}

The respondents were ask on the best medium through which assistance can be provided and it was seen that that users orientation was the highest requirement of the respondent with $72 \%$ of the total population feeling the need of users orientation. 


\begin{tabular}{lcccc}
\hline & Ph.D & M.A & Mphil & total \\
\hline user & 4 & 58 & 10 & 72 \\
orientation & & 10 & & \\
personal & 0 & 8 & 0 & 10 \\
per group & 1 & 0 & 0 & 9 \\
others & 0 & & & \\
& & & & \\
\hline
\end{tabular}

Table14: Modes of assistance

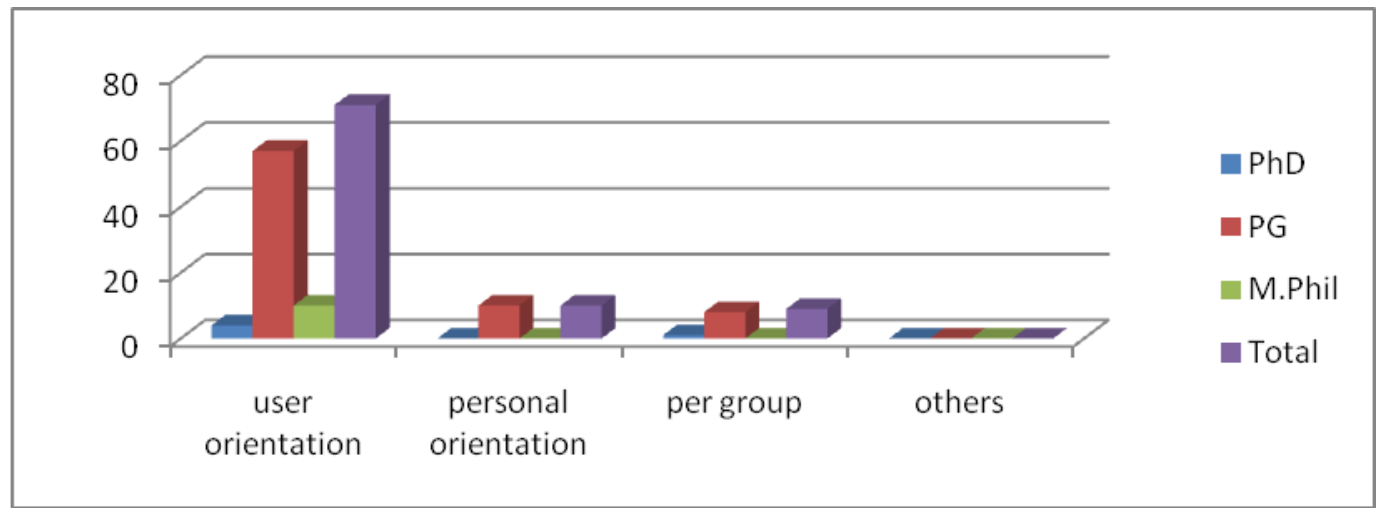

Figure 11: Modes of assistance

\section{Limitation of the study:}

Although the study threw a few lights to the Wi-Fi facility in Pondicherry University there is always a room for improvement. An approach to Users awareness study is in itself a diverse area and therefore the study is limited to a given sample population. With limited time frame, coverage on the users view and cost benefit analysis was not incorporated. User's perception on familiarities and the technical aspect of the facility were avoided and was confine to awareness and the student usage of campus Wi-Fi. The demographic characteristics of year of study and college enrollment for the sample were similar to those of both university student enrolment to the hostel and the university student population. However, the small sample sizes 
were subject to variance equality problems when analyzing results based upon groups. Male participants significantly outnumbered female participants.

While general conclusions could be drawn regarding results as applied to the residential student body, the sample does not reflect the attitudes of non residential students, which may be different, compared to those of residential students despite similar demographic variables. Documenting the disparity between commuter and residential students is an area for future research.

\section{CONCLUSION AND SUGGESTION:}

The findings of the study suggest that there is a high level of ICT awareness among student and that the demographics of survey participants varied in terms of age, education levels and the subject. From a sample population of 100 respondents, fifty eight (58) were male and forty two (42) were female with an ages ranging between 20 and 29 years-old. Post graduate responded maximum with $85 \%$ which constituted $46 \%$ male and $39 \%$ female. M.Phil on the other hand constituted the second highest with $10 \%$ and Ph.D scholars with $5 \%$ of the total sample group. Computer literacy among student of Pondicherry looks pretty good with 99\% of the students stating that they have either use or are using computer.

Social Science constitutes the highest number of participant with $69 \%$ and entertainment was one of their main purposes driven in using computer. High percentage (79\%) of the population is aware of the presence of $\mathrm{Wi}-\mathrm{Fi}$ and $85 \%$ of the total populations have use Wi-Fi facility were a majority (66\%) feels hostel to be the best location for surfing. It was also found that laptop seems to be the favorite gadget in accessing Wi-Fi. On being asked about the speed of the connectivity, $77 \%$ of the respondent were not happy with the speed and have come across technical snag and errors. On the other side of the story, the respondent (72\%) feels that orientation on the use or assistance is required for better usage of $\mathrm{Wi}-\mathrm{Fi}$ within the campus.

Today's environment is characterized by an increasingly mobile workforce and flatter organizations. Individuals are equipped with notebook computers and spend more of their time 
working in teams that cross functional, organizational, and geographic boundaries. Much of these students productive learning occurs in meetings and away from their desks. Users needs are not confine to a define location but, far beyond their personal desktops. WLANs fit well in this working environment, giving mobility to students and much-needed freedom in their search for information. With a wireless network advantage, students can now have access to a wide range of information from any given hotspots - the cafeteria, library or a remote hostels. With this advantage universities can benefit from deploying a WLAN system, which provides a powerful combination of wired network throughput, mobile access, and configuration flexibility. The usage of the electronic resources will add up the increase in usage statistic of scholarly resources. Specifically, WLAN advantages include:

- Mobility that improves productivity with real-time access to information, regardless of student's field of study location, for faster and more efficient decision-making

- Cost-effective network setup for hard-to wire locations such as older buildings and solidwall structures

- Reduced cost of ownership - particularly in dynamic environments requiring frequent modifications - thanks to minimal wiring and installation costs per device and user WLANs liberate users from dependence on hard-wired access to the network backbone, giving them anytime, anywhere network access. This freedom to roam offers numerous user benefits for a variety of work environments.

Given into account the findings, for better usage of Wi-Fi facility, it is therefore a need of an hour to better understand the problems face by the users in their daily use of the system.

1. Networking management system should be able to identify and rectify the errors of every hotspot in the campus.

2. Awareness should be conducted on the availability of the electronic resources of the university.

3. User's orientation in the first year of their enrolment should be conducted for familiarizing them with the facilities available.

4. Financial subsidy should be provided to the student and a M.O.U with local supplier should be provided for increasing usage and building ICT awareness. 
5. Increase in the number of hotspot should be encouraged and better equipments for better signal should be installed.

6. High bandwidth should be provided so as to enable the students in downloading electronic resources.

7. Restriction to multiple sites and streaming videos should be minimized so as to enable high usage of the academic resource available.

Therefore, there is an urgent need on the administration part to incorporate some of the grievances of the student community and take into account the research findings of this small study. For, the presence of Wi-Fi within the campus is a boon to the university student in accessing electronic resources and for academic perusal. There is always a room for improvement.

\section{REFERENCES:}

1. Lundin, Johan et.al (2010). Integrating students' mobile technology in higher education. Int. J. Mobile Learning and Organisation, Vol. 4.

2. Barak, M., Lipson, A., and Lerman, S (2006). Wireless laptops as means for promoting Active learning in large lecture halls. Journal of Research on Technology in Education, 38(3), 245-263.

3. Beasley, W., Dobda, K.W., \& Wang, L.C. (2005). Reflections on teaching in a wireless laptop lab. International Journal of Instructional Media, 32(4), 343-352.

4. Bina, M. \& Giaglis, G.M. (2005). Emerging issues in researching community-based WLANS. The Journal of Computer Information Systems, 46(1), 9-16.

5. Bina, M. \& Giaglis, G.M. (2005). Emerging issues in researching community-based wlans. The Journal of Computer Information Systems, 46(1), 9-16.

6. Campus Computing Project (2002). The 2002 National Survey of Information Technology in U.S. Higher Education. Encino, CA: USA.

7. Chang, S., Yu, H., \& Tsai, J. (2006). How to operate public wlan business: The case of Taiwan. Journal of American Academy of Business, Cambridge, 8(1), 253-259.

8. Chen, L. \& Nath, R. (2006). An empirical examination of the impact of wireless local area network on organization of users. Journal of Electronic Commerce in Organizations, $4(2), 62-81$. 
9. Chen, L. and Nath, R. (2006). An empirical examination of the impact of wireless local area network on organization of users. Journal of Electronic Commerce in Organizations, $4(2), 62-81$.

10. Cox, J. (2007). Two wireless LANs better than one, Carnegie Mellon says. Retrieved electronically on February 12,

11. Crews, T.B., Brown, H.F., Bray, S., \& Pringle, E.M. (2007). Student campus technology trends: 2001 versus 2006. EDUCAUSE Quarterly, 30(4), 30-36.

12. Davis, F.D. (1989). Perceived usefulness, perceived ease of use, and user acceptance of information technology. MIS Quarterly, 13(3), 319-340.

13. Drew, W. (2003). Wireless networks: New meaning to ubiquitous computing. The Journal of Academic Librarianship, 29(2), 102-106.

14. East Carolina University (2001). Effective practice detail: The handheld computer and wireless connectivity.EDUCAUSE: Submitted April 2, 2001. Retrieved electronically on September 30, 2006.

15. East Carolina University. (2001). Effective practice detail: The handheld computer and wireless connectivity. EDUCAUSE: Submitted April 2, 2001. http://www.networkworld.com/news/2007/121107-carengie-mellon-wirelesslans.html (Accessed on $12^{\text {th }}$ Feb 2010)

16. Kim, J.O. \& Mueller, C.W. 1978. Introduction to factor analysis. Beverly Hills, CA: Sage University Press.

17. Kotz, D and Essien, K. (2005). Analysis of a campus-wide wireless network. Wireless Networks, 11, 115-133.

18. Lehner, F., Nosekabel, H., and Lehmann, H. (2003). Wireless E-learning and communication environment. E-Service Journal, 2(3), 23-41.

19. Lu, J., Liu, C., Yu, C.S. \& Ku, C.Y. (2004). Wireless trust conceptual and operational definition. International Journal of Mobile Communications, 2(1), 38-50.

20. Lu, J., Yu, C.S. Liu, C. \& Yao, J.E. (2003). Technology acceptance model for wireless internet. Internet Research, 13(3), 206-222.

21. Powell, Alison (2008) 'WIFI PUBLICS', Information, Communication \& Society, 0: 0, $1068-1088$.

22. Robert, Romain et.al (2008) Wi-Fi Roaming: Legal Implications and Security Constraints. International Journal of Law and Information Technology, 16(3) 